\title{
Perceived Social Support among HIV Positive and HIV Negative People in Ibadan, Nigeria
}

\author{
Oluyemisi Folake Folasire ${ }^{1,2 *}$, Odun Akinyemi ${ }^{3}$, Eme Owoaje ${ }^{4}$ \\ ${ }^{1}$ Department of Family Medicine, University College Hospital, Ibadan, Nigeria \\ ${ }^{2}$ Department of Human Nutrition, University of Ibadan, Ibadan, Nigeria \\ ${ }^{3}$ Department of Epidemiology and Medical Statistics, University of Ibadan, Ibadan, Nigeria \\ ${ }^{4}$ Department of Community Medicine, University of Ibadan, Ibadan, Nigeria \\ Email: ${ }^{*}$ yemisifolasire2011@gmail.com, offolasire@comui.edu.ng
}

Received 18 November 2013; revised 18 December 2013; accepted 25 December 2013

Copyright (C) 2014 by authors and Scientific Research Publishing Inc.

This work is licensed under the Creative Commons Attribution International License (CC BY).

http://creativecommons.org/licenses/by/4.0/

(c) (i) Open Access

\section{Abstract}

Background: People living with HIV and AIDS (PLWHA) are assumed to have poor social support. This study compared the satisfaction with perceived social support of people living with HIV and AIDS with HIV negative patients. Method: 150 HIV positive patients were age and sex matched with 150 HIV negative patients in a cross sectional comparative study. Information on socio-demography and social support was assessed with questionnaire including multidimensional scale of perceived social support (MSPSS). Chi square test, student t-test, and linear regression analysis were done at $p=0.05$ level of significance. Result: Mean age of the HIV positive versus HIV negative patients is $38.1 \pm 9.0$ years versus $37.7 \pm 9.2$ years. Both groups had the lowest social support scores from family, (FA): $3.81 \pm 1.08$ vs $3.95 \pm 0.89, p=0.240$. Perceived support from friends (FR) was higher in the HIV negative group $7.41 \pm 1.99$ vs $5.55 \pm 2.34, p=0.000$ as well as perceived total support (TS), $3.94 \pm 0.68$ vs $3.59 \pm 0.77, p=0.000$. Linear regression for all the respondents revealed HIV status contributed the most and predicted TS and FR scores respectively $(\beta=-0.18195 \%$ C.I $=-5.843$ to $-0.766, p=0.010$ and $\beta=-0.317,95 \%$ C.I, -4.260 to $-1.792, p=0.000$ ). For PLWHA group, employment contributed most to perceived TS $(\beta=-0.18195 \%$ C.I -11.812 to $-0.0361, p=$ 0.049). However, in HIV negative group, TS and FR had the greatest contribution from marital status, $(\beta=-0.41695 \%$ C.I -6.157 to $-1.829, p=0.000)$ and $(\beta=-0.38195 \%$ C.I -2.851 to -0.756 , $\mathrm{p}=0.001)$. Also, the current living status $(\beta=-0.268,95 \%$ C.I -3.238 to $-0.360, p=0.015$, and $\beta=$ $\mathbf{- 0 . 2 4 1} 95 \%$ C.I -1.48 to $-0.09, p=0.027)$. Conclusion: All respondents had the poorest perception of support from family (FA). Lack of employment is the most important factor identified in this group of PLWHA, responsible for the poor TS. For the HIV negative group, not being married and living outside family setting were the strongest factors for poor social support.

\footnotetext{
*Corresponding author.
} 


\section{Keywords}

\section{HIV and AIDS; Social Support; MPSSS; Nigeria}

\section{Introduction}

Life expectancy in people living with HIV and AIDS (PLWHA) has increased tremendously with the successes of anti-HIV medications which have transformed HIV to a chronic disease. Chronic conditions refer to ailments with which patients live with for many months or years, with resultant increase demand for care and support. In order to fulfill the demand for care and treatment, family, friends, and the community can be major sources of support [1]. Perceived social support (PSS) refers to the beliefs or evaluations that one has about the relationships in one's life [2]. Social support is said to be the feeling of being cared for, loved, valued and esteemed or being able to count on other people if a need arises. [3]. It also refers to the perceived comfort, care, esteem, or help a person receives from other people or groups [3].

Social support in actual practice can be given or received; secondly, it can be seen as availability versus utilization of sources of support. Thirdly, expressed in terms of type of support versus evaluation of satisfaction with support. Fourthly, in what form does the support take? And lastly, what social structure provides the support: family, friends, and significant others [4] [5].

Some individuals are able to identify special persons not necessarily related to them and considered as "significant others" as a source of social support. It may be a parent, teachers, colleagues, pastors (spiritual leaders) and close friends [1] [6]. Researchers agree that the person as well as the situation affects perceived social support, and that the concept deals with the interaction between individual and social variables [6]. Social support may not be considered useful unless the individual perceives it as supportive. Thus, the perception is a better predictor of health outcomes than the receipt [1].

\section{Background}

\subsection{Perceived Social Support in PLWHA}

With regards to care of PLWHA, two sources of support have been identified and proved functional. The first relates to family and friends, and the second to community-based support, government agencies, and the health care industry [1]. This non-family support also include those relating to nursing practice and care of PLWHA as information provided for referral and counseling by counselors, health workers. Medical treatment given is considered tangible support. This support was found to be greater than family support network in a recent study on PLWHA in Nepal [1].

Support from families and others has been reported to have either positive or negative effect after disclosure, satisfaction with family support was reported to have helped PLWHA overcome depression, reduce high-risk behaviors, seek medical treatment, and go on with life normally, this finding was also reported to encourage safer sex practice and is best positive predictor of medication adherence in PLWHA [7]-[9]. Positive support from friends and family is valuable to counter stigma this finding was also reported in a study on African-American from an HIV social service agency that only perceived social support from friends was found to be related to reduced perceived stigma [1]-[3].

Different cultures may have different perceptions of support. African-American men compared to their counterpart HIV-infected older white men reported more support from family members, and were less likely to disclose their HIV sero-status to close friends due to stigma [10].

The health benefits of satisfaction with social support has also been reported in children living with HIV, vulnerable children have low levels of perceived social support (PSS), and high level of PSS is associated with better psychological heath [11]-[13].

Greater perceived social support from friends has been associated with a lower negative self-image about being HIV positive [2]. Family members, particularly spouses or partners, appear to be the most important source of social support, and account for most of the association between social support and health. There is evidence that support from sources outside the family cannot compensate for what is missing in the family and that the 
family is the main source of care and support for PLWHA in most developing countries [14] [15]. Also, siblings and special persons can be effective sources of social support for PLWHA [11] [12].

In a recent study in Nigeria, where the family and community were actively involved in care and support of PLWHA, there was better perception of psychological care received from family than from community, and improvement in community based care has shown to improve the wellbeing of PLWHA [16].

Various types of support like informational, instrumental, and emotional may be needed in varying combinations at different stages in the process of HIV infection. Various forms of support rendered to PLWHA by family members is documented, such as accompanying the patients to the health facilities, paying hospital bills, some prayed, some provided financial assistance, psychosocial and emotional support [15] [17]. Although all types of social support were associated with reduced depression, informational support was especially beneficial for those in early stages of the disease [18]. Also, better perception of social support from peers and non-parental figures has been associated with greater condom use behavior among young urban slum inhabitants in southwest Nigeria [19].

Being HIV positive does not necessarily translate to poor social support. This is because social support is not only regarded as availability of support but rather its perceived adequacy [1]. This concept is also confirmed in studies, where HIV positive status was associated with higher perceived social support [12] [20].

\subsection{Rationale for the Study}

There is now an awareness that patient's experience, attitudes, beliefs, emotions, relationships, and social environment intermingle in a system which affect the feeling of illness or well-being [3]. Based on this, it is very important to integrate psychosocial data (such as family structure, functioning, social support networks and significant others) about a particular patient with concrete understanding, to inform effective interventions.

\subsection{Justification}

There are few published works on the satisfaction with perceived social support of PLWHA in Nigeria, though there are many works on their social support needs. And as at the time of the study, there are paucity of publication in PLWHA, addressing satisfaction with perceived social support from family, friends and significant others, using the multidimensional scale of perceived social support (MPSS).

The objective of the study was to, compare the perceived social support of PLWHA with HIV negative persons in Ibadan, Nigeria and determine what factors interact to affect their satisfaction with perceived social support from family, friends and significant others.

\section{Methodology}

\subsection{Study Site and Population}

The HIV sero-positive patients were recruited from the Aids Prevention Initiative of Nigeria (APIN-plus) antiretroviral clinic, University College Hospital (UCH), Ibadan, Nigeria. The HIV sero-negative patients were regular attendees of the Family medicine department's clinic, of the same teaching hospital. Ibadan is the capital of Oyo state, the largest southwestern state in Nigeria, located $128 \mathrm{~km}$ inland northeast of Lagos and $530 \mathrm{~km}$ southwest of Abuja, the federal capital of Nigeria. Ibadan has a population of about 1.3 million and Oyo state's HIV prevalence is 3.0\% [21] [22]. The APIN-plus clinic, U.C.H. has been in existence since 2004, offering holistic care to PLWHA by team of Family Physicians and other specialists. Through the support of the Federal Government of Nigeria and part contribution of PEPFAR, services such as provision of free antiretroviral, other medications, laboratory investigations, consultation fee waiver, admission charges, psychotherapy and some nutritional counseling is offered among others.

\subsection{Study Design}

Cross-sectional comparative study was done between June and September 2008 amongst HIV sero-positive patients and HIV sero-negative patients who were being managed for other chronic diseases such as uncomplicated hypertension and type II diabetes mellitus. 


\subsection{Sample Size}

Minimum sample size of 150 per study group was calculated using standard formula for comparative study assuming a difference of $15 \%$ in satisfaction in perceived social support between HIV positive and HIV negative group [23].

\subsection{Sample/Data Collection Technique}

150 HIV sero-positive patients (Western blot positive) were randomly selected using Microsoft excel 2003 random number generator. This was drawn from the daily clinic attendance list, at a regular time each clinic day. A total of one hundred and sixty PLWHA were approached, only ten declined to participate giving a response rate of about 94\%. They were age and sex matched with 150 HIV sero-negative patients, previously screened with double rapid screening for HIV 1 \& 2 (Determine and Unigold HIV 1 \& 2 screening kits) at the Family Medicine clinic after HIV counseling. Informed consent was taken from every respondents and confidentiality was assured.

\subsection{Study Instrument}

Interviewer administered questionnaire was used to collect information on socio-demographic data and satisfaction with Social support was assessed with the multidimensional scale of perceived social support (MPSSS) [4].

The MSPSS questionnaire is comprised of 12 items rated on a 5-point Likert-type scale (response format ranges from, 1 = strongly disagree to 5 = strongly agree). A higher score signifies increased levels of perceived social support. The score on individual items on the MSPSS were summed and divided by 12 . Scores on the four items that comprise each subscale were also summed and divided by 4 . The total MSPSS has been reported to have high internal consistency with Cronbach's alpha of 0.86 [4], in the current study it was 0.77 for the HIV positive group and 0.82 for the HIV negative group.

The MPSSS assessed satisfaction with social support from family (FA), Friends (FR), and significant others (SO). For this study, a significant other was explained as a special person or an individual that respondent feels closer to besides family and friends and can discuss personal issues with. Significant other is someone not necessarily related to the individual such as church leaders/members, teachers, colleagues and closer friends. In the Nigerian context, individuals could be living with their children in the individual's home, with or without a partner. On the other hand, the individual could have moved into a child's house, a friend's or significant other's house. Hence the current living status considered living within respondent's family setting or outside it.

This article addresses an aspect of a larger study on PLWHA in Nigeria, with details of services provided at the APIN- UCH antiretroviral clinic, University College Hospital, Nigeria earlier documented [24].

\subsection{Ethical Considerations}

Permission was granted by the University of Ibadan/University College Hospital Joint Institutional Review Board. Consent was obtained from the patients after explaining the study to them.

Validity: The MPSSS questionnaire had been previously validated [4] developed in English, but translated to Yoruba, the local language in southwestern Nigeria and back translated to English. Used only in few patients not fluent in English. The questionnaire was pretested at another clinic and modified for clarity. Cronbach's alpha for the study was 0.77 and 0.82 for HIV sero-positive and HIV sero-negative groups respectively. The questionnaire were administered (in about 25 minutes as part of a larger study), by Masters level psychology students previously trained on the instrument and re-trained after half of the sample size were recruited. Each questionnaire was immediately cross-checked by the researching physician. Respondents were informed they were free to decline from participating; questionnaire was pre-coded to ensure anonymity.

\subsection{Data Analysis}

The statistical analysis was done with SPSS version 16. Categorical variables were crosstab and analyzed with chi square. MPSSS was reported as mean scores with Mann-Whitney U-test. Multiple regression analysis was done, using enter mode function of SPSS. Age, sex, marital status, educational and employment status, social class index, number of children, current living status were re-coded and entered as independent variables, to de- 
termine their relative contribution to the significantly different MPSSS components (TS and FR). First, for all respondents together, and later HIV sero-positive and HIV sero-negative respondents separately.

The independent variables were weakly correlated in the bivariate analysis and the collinearity diagnostic function in SPSS, gave tolerance values of less than 10 and variance inflation factor of less than 10 for all the regression models, thus effect modification was not needed. Level of significance was set at 0.05 . The social class structure of the respondents was assessed using the occupation index from a Nigerian study [25].

\section{Results}

\subsection{Socio-Demographic Profile}

A total of 300 respondents participated in the study. The response rate was about $94 \%$. The mean age of the HIV positive vs HIV negative respondents is $38.1 \pm 9$ vs $37.7 \pm 9$ years, male:female ratio: 1:2.

Majority ( $\mathrm{n}=101,67.4 \%$ vs $\mathrm{n}=95,64.0 \%)$ in both groups were married, higher proportion of PLWHA $(\mathrm{n}=$ $12,8.0 \%, 18,12.0 \%)$ were separated or widowed compared with HIV negative respondents $(n=4,2 \%$ and 2 , 1.3\%) 54 (36.0\%) of PLWHA had completed secondary school education compared with 35 (23.3\%) of the HIV negative respondents.

Most ( $\mathrm{n}=106,71.6 \%$ ) of the HIV positive respondents were of lower social class index compared with majority $90(60.0 \%)$ of the HIV negative group. Most $(n=66,52 \%)$ PLWHA had one or two children compared with 27 (27\%), HIV negative respondents. In both groups, most $(n=128,85.3 \%$ vs $n=122$, 81.3\%) were living within their family setting. However, none of the HIV negative respondents was living with a friend. Comparison of the profile is shown in Table 1.

\subsection{Perceived Social Support Scores (MPSSS)}

The mean perceived social support scores of the respondents as shown in Table 2. Both group of respondents had the lowest MPSS scores from the family (FA).

Linear regression analysis for the significantly different MPSSS domains i.e. Total support (ST) and support from friends (FR) shown in Tables 3-5. For all respondents, HIV status contributed the most and predicted the perceived TS and FR scores, Table 3.

For only HIV sero-positives, employment status had the most contribution to perceived TS, as shown in Table 4. For HIV sero-negatives, marital status and current living status respectively made the most contribution to the perceived TS and FR scores, shown in Table 5.

\section{Discussion}

The aim of the study was to compare the satisfaction with perceived social support of PLWHA and HIV negative respondents and to determine social variables responsible for the perceived social support scores. It is important to note that only few studies had compared the perceived social support in this context. This article thus report part of a larger study.

Most of the HIV positive respondents were within 15 and 45 years of age with modal age group of 30 - 39 years. This was similar to previous studies done in Nigeria and other parts of the world [5] [16] [17] [26] [27]. All in support that HIV/AIDS is a disease mainly affecting the reproductive age group and the work force of a nation [28]-[30]. None of the HIV positive respondent studied was living alone which was different from what an earlier study reported, where $10 \%$ of the PLWHA studied were living alone, though in a rural setting [5]. Higher proportion of HIV positive respondents were living within their own family setting, either living with partners and children, or with their children compared to the HIV negative group. Also, fewer PLWHA were living outside their family setting (living with friends and significant others) compared with HIV negative group. This probably implies that the HIV positive study group seemed to have stable relationships and may enjoy better social support from their partners. However, it is important to note that this study reported both HIV positive and negative respondents perceived the least support scores from family (FA), as indicated in Table 2. Though, this finding could be attributed to Africans' cultural views. That it is obligatory "duty" for family to provide support, which is not perceived as "special" and therefore does not provide satisfaction. In other societies where the government provides most social support, family support may be perceived as special. 
Table 1. Comparison of socio-demographic profiles of HIV positive and HIV negative patients.

\begin{tabular}{|c|c|c|c|}
\hline Variable & HIV Positive & HIV Negative & p value \\
\hline \multicolumn{4}{|l|}{ Age group (yrs) } \\
\hline $20-29$ & $24(16.0)$ & $36(24.0)$ & \\
\hline $30-39$ & $66(44.0)$ & $46(30.7)$ & \\
\hline $40-49$ & $44(29.3)$ & $50(33.3)$ & \\
\hline 50 and $>$ & $16(10.7)$ & $18(12.0)$ & 0.091 \\
\hline \multicolumn{4}{|l|}{ Marital status } \\
\hline Single & $16(10.6)$ & $46(30.7)$ & \\
\hline Married & 101(67.4) & $95(64.0)$ & \\
\hline Divorced & $3(2.0)$ & $3(2.0)$ & \\
\hline Separated & $12(8.0)$ & $4(2.0)$ & \\
\hline Widowed & $18(12.0)$ & $2(1.3)$ & $0.003^{*}$ \\
\hline \multicolumn{4}{|l|}{ Educational status } \\
\hline No formal education & 16(10.7) & $8(5.3)$ & \\
\hline Primary School & 29(19.3) & 20(13.3) & \\
\hline Secondary (uncompleted) & $14(9.3)$ & $13(8.8)$ & \\
\hline Secondary (completed) & $54(36.0)$ & $35(23.3)$ & \\
\hline Post Secondary & $37(24.7)$ & 74(49.3) & $0.000^{*}$ \\
\hline \multicolumn{4}{|l|}{ Social Class } \\
\hline I & $2(1.3)$ & $7(4.7)$ & \\
\hline II & $22(14.7)$ & $43(28.7)$ & \\
\hline III & 20(13.3) & $10(6.7)$ & \\
\hline IV & 29(19.3) & $21(14.0)$ & \\
\hline $\mathrm{V}$ & $63(42.0)$ & $47(31.3)$ & \\
\hline VI & $14(9.3)$ & $22(14.7)$ & $0.003^{*}$ \\
\hline \multicolumn{4}{|l|}{ Number of children } \\
\hline 0 & 23(15.3) & $50(33.3)$ & \\
\hline $1-2$ & $66(44.0)$ & $27(18.0)$ & \\
\hline $3-4$ & $38(25.3)$ & $44(29.3)$ & \\
\hline$>5$ & 23(15.3) & 2919.3) & $0.001^{*}$ \\
\hline \multicolumn{4}{|l|}{ Current living status } \\
\hline Alone + children & $96(64.0)$ & $98(65.3)$ & \\
\hline Alone + partner & $9(6.0)$ & 20(13.3) & \\
\hline Partner + children & 23(15.3) & $4(2.7)$ & \\
\hline Friends & $3(2.0)$ & $0(0.0)$ & \\
\hline Significant other & 19(12.7) & 28(18.7) & $0.001^{*}$ \\
\hline
\end{tabular}

*Significant at $\mathrm{p}<0.05$.

\subsection{Multidimensional Scale of Perceived Social Support (MPSSS) Scores}

The HIV positive and negative groups perceived poorest support from their families (FA). HIV positive respondents had the lowest support scores from their family, followed by significant other (SO), and the highest per- 
Table 2. Comparison of perceived social support scores of the HIV positive and HIV negative patients Using MPSSS 2008.

\begin{tabular}{cccc}
\hline Perceived Social Support & $\begin{array}{c}\text { HIV Positive } \\
\text { Mean score } \pm \text { SD (N = 150) }\end{array}$ & $\begin{array}{c}\text { HIV NEGATIVE Mean } \\
\text { score } \pm \text { SD (N = 150) }\end{array}$ & p value \\
\hline Significant Other (SO) & $4.09 \pm 0.89$ & $4.18 \pm 0.68$ & 0.87 \\
Family (FA) & $3.81 \pm 1.08$ & $3.95 \pm 0.87$ & 0.24 \\
Friend (FR) & $5.55 \pm 2.34$ & $7.41 \pm 1.99$ & $0.00^{*}$ \\
Total Support (TS) & $3.59 \pm 0.77$ & $3.94 \pm 0.68$ & $0.00^{*}$ \\
\hline
\end{tabular}

*Significantly different between HIV positive and HIV negative patients.

Table 3. Linear regression analysis models of all respondents together.

\begin{tabular}{|c|c|c|c|c|c|c|}
\hline \multirow{2}{*}{ Variables } & \multicolumn{3}{|c|}{ Perceived Total Support } & \multicolumn{3}{|c|}{ Perceived Support From Friends } \\
\hline & $\beta$ coefficient & 95\% C.I & $p$ value & $\beta$ coefficient & 95\% C.I & $p$ value \\
\hline $\begin{array}{c}\text { Age } \\
<40 \text { years }^{\dagger} \\
>40 \text { years }\end{array}$ & 0.074 & -0.85 to 2.38 & 0.35 & 0.063 & -0.44 to 1.13 & 0.39 \\
\hline $\begin{array}{l}\text { Sex } \\
\text { Male† } \\
\text { Female }\end{array}$ & 0.021 & -2.32 to 3.10 & 0.78 & -0.022 & -1.54 to 1.10 & 0.74 \\
\hline $\begin{array}{c}\text { Marital status } \\
\text { Married }^{\dagger} \\
\text { Not married }\end{array}$ & -0.113 & -1.81 to 0.23 & 0.13 & -0.094 & -0.84 to 0.15 & 0.17 \\
\hline $\begin{array}{c}\text { Educational level } \\
<9 \text { years } \\
>9 \text { years }\end{array}$ & 0.100 & -0.31 to 1.65 & 0.18 & -0.013 & -0.52 to 0.43 & 0.86 \\
\hline $\begin{array}{c}\text { Employment status } \\
\text { Employed }^{\dagger} \\
\text { Unemployed }\end{array}$ & -0.103 & -7.99 to 1.07 & 0.13 & -0.069 & -3.41 to.099 & 0.28 \\
\hline $\begin{array}{l}\text { Social class } \\
\text { High }^{\dagger} \\
\text { Low }\end{array}$ & 0.018 & -0.94 to 1.19 & 0.82 & -0.053 & -0.71 to 0.33 & 0.47 \\
\hline $\begin{array}{c}\text { Number of children } \\
<=4^{\dagger} \\
>4\end{array}$ & 0.053 & -1.18 to 2.41 & 0.50 & 0.170 & 0.16 to 1.91 & $0.02^{*}$ \\
\hline $\begin{array}{l}\text { Current living status } \\
\text { Within family setting }^{\dagger} \\
\text { Outside family setting }\end{array}$ & $\begin{aligned} 0.040 & \\
\text { Adjusted } \mathrm{R}^{2} & =0.05\end{aligned}$ & $\begin{array}{c}-0.60 \text { to } 1.13 \\
F=2.42\end{array}$ & $\begin{array}{c}0.55 \\
P=0.01\end{array}$ & $\begin{array}{c}0.049 \\
\text { Adjusted } \mathrm{R}^{2}=0.18\end{array}$ & $\begin{array}{c}-0.25 \text { to } 0.59 \\
F=6.55\end{array}$ & $\begin{array}{c}0.43 \\
P=0.00\end{array}$ \\
\hline
\end{tabular}

${ }^{\dagger}$ Reference category, ${ }^{*}$ Significant at $(\mathrm{p}<0.05)$; All respondent together, HIV positive status was the best significant predictor. Being HIV positive gave a 0.181 unit reduction in perceived TS and 0.317 unit reductions in support from FR.

ceived support was from their friends (FR). There seems to be no consensus from previous studies. The family gave the least support, while friends, lovers with significant others were the most common sources of emotional support in a study [18]. Current finding is in contrast to Galvan's finding, that support from friends followed by family was better than from a special person [3].

Another reason for poorer perceived social support from FA, may be a reflection of the negative effect that separation, divorce or widowhood have on the satisfaction with support from family. In this study, higher proportion of PLWHA were separated, divorced or widowed compared with their HIV negative counterparts. This was similar to what was reported on the effect of HIV/AIDS on family support system, family members carry a lot of burden, in caring for PLWHA, especially when they fall sick [17]. Caring for PLWHA can be very stressful and time consuming, coupled with the economic and financial burden that HIV/AIDS brings. These may make PLWHA have a poor perception; of the support they get from those they call, "family" especially once, 
Table 4. Linear regression analysis models of HIV sero-positive respondents alone.

\begin{tabular}{|c|c|c|c|c|c|c|}
\hline \multirow{2}{*}{ Variables } & \multicolumn{3}{|c|}{ Perceived Total Support } & \multicolumn{3}{|c|}{ Perceived Support From Friends } \\
\hline & $\beta$ coefficient & 95\% C.I & p value & $\beta$ coefficient & 95\% C.I & p value \\
\hline $\begin{array}{c}\quad \text { Age } \\
<40 \text { years } \\
>40 \text { years }\end{array}$ & 0.155 & -0.77 to 4.09 & 0.18 & 0.175 & -0.27 to 2.13 & 0.13 \\
\hline $\begin{array}{c}\text { Sex } \\
\text { Male }^{\dagger} \\
\text { Female }\end{array}$ & 0.013 & -3.87 to 4.35 & 0.91 & -0.037 & -2.38 to 1.68 & 0.74 \\
\hline $\begin{array}{c}\text { Marital status } \\
\text { Married }^{\dagger} \\
\text { Not married }^{-}\end{array}$ & -0.051 & -1.55 to 0.92 & 0.62 & -0.053 & -0.77 to 0.45 & 0.61 \\
\hline $\begin{array}{c}\text { Educational level } \\
<9 \text { years }{ }^{\dagger} \\
>9 \text { years }\end{array}$ & 0.133 & -0.51 to 2.35 & 0.20 & 0.021 & -0.633 to 0.78 & 0.08 \\
\hline $\begin{array}{c}\text { Employment status } \\
\text { Employed }^{\dagger} \\
\text { Unemployed }\end{array}$ & -0.181 & -11.81 to -0.04 & $0.04^{*}$ & -0.043 & -3.61 to 2.20 & 0.06 \\
\hline $\begin{array}{c}\text { Social class } \\
\text { High }^{\dagger} \\
\text { Low }\end{array}$ & -0.005 & -1.62 to 1.54 & 0.96 & -0.032 & -0.90 to 0.66 & 0.76 \\
\hline $\begin{array}{c}\text { Number of children } \\
<=4^{\dagger} \\
>4\end{array}$ & 0.014 & -2.54 to 2.89 & 0.90 & 0.142 & -0.50 to 2.18 & 0.21 \\
\hline $\begin{array}{l}\text { Current living status } \\
\text { Within family setting }^{\dagger} \\
\text { Outside family setting }\end{array}$ & $\begin{aligned} 0.171 & \\
\text { Adjusted } \mathrm{R}^{2} & =0.04\end{aligned}$ & $\begin{array}{c}-0.03 \text { to } 2.20 \\
F=1.59\end{array}$ & $\begin{array}{c}0.06 \\
p=0.14\end{array}$ & $\begin{array}{c}0.154 \\
\text { Adjusted } \mathrm{R}^{2}=0.04\end{array}$ & $\begin{array}{c}-0.07 \text { to } 1.03 \\
F=1.65\end{array}$ & $\begin{array}{c}0.09 \\
P=0.12\end{array}$ \\
\hline
\end{tabular}

${ }^{\dagger}$ Reference category; ${ }^{*}$ Significant at $(\mathrm{p}<0.05)$; For the HIV positive group, the TS is best predicted by employment status, those not employed had a significant 0.181 unit reduction in perceived TS.

the support from family members starts to dwindle, as the disease progresses.

Abandonment is another social problem that PLWHA are faced with. The discordant couples are not left out when the spouse refuse to be supportive, but abandon the PLWHA, leading to poor perception of support from the family. All these confirm the negative influence that the family may have in health and may be seen as a need in both groups of respondents studied. The lack of significant difference in perceived support from family of both HIV positive and HIV negative respondents in this study raises question of what Nigerians expects from their family, which future studies on PSS can address.

Some researchers have reported that support from significant others ("a special person") in PLWHA include the support from lovers, support networks, hospital personnel and priests; whom they can talk to, receive advice and counsel, [18] [30] the APIN-plus clinic, U.C.H. gives them an opportunity to interact with health personnel as well as opportunity to join support groups or network. By participating in these support group network, some financial burdens are actually taken-off the PLWHA. Through organised group transportation for clinic visits. Also, PLWHA studied had access to free antiretroviral medications, consultation fee and other hospital bills are waived [24]. This may somewhat encourage most of them to feel they do not need their family especially to provide finances for their medical treatment, since its free, and so do not feel any family member should know of their HIV status, except when they are really ill and need admission. When a member is not able to present in clinic for the regular drug pickup, often due to tight schedule at work, a member of the support network can collect the ARVs on the behalf of the patient. They can also, make a phone call to the clinic and make arrangement for their medications to be courier to them, including those working outside the shores of Nigeria. In contrast to the HIV negative groups, who often than not have to pay hospital bills out of pocket. The few civil servants amongst them access the national health insurance thus buffering their hospital bills.

Using regression analysis, it is interesting to note that the differences in the perceived social support observed among the two groups of respondents seem to have different contributing factors. 
Table 5. Linear regression analysis models of HIV sero-negative respondents alone.

\begin{tabular}{|c|c|c|c|c|c|c|}
\hline \multirow{2}{*}{ Variables } & \multicolumn{3}{|c|}{ Perceived Total Support } & \multicolumn{3}{|c|}{ Perceived Support From Friends } \\
\hline & $\beta$ coefficient & 95\% C.I & $p$ value & $\beta$ coefficient & 95\% C.I & $p$ value \\
\hline $\begin{array}{c}\quad \text { Age } \\
<40 \text { years } \\
>40 \text { years }\end{array}$ & 0.003 & -2.08 to 2.14 & 0.98 & -0.040 & -1.20 to 0.84 & 0.72 \\
\hline $\begin{array}{c}\text { Sex } \\
\text { Male }^{\dagger} \\
\text { Female }\end{array}$ & 0.099 & -1.82 to 5.15 & 0.35 & 0.050 & -1.24 to 2.14 & 0.60 \\
\hline $\begin{array}{c}\text { Marital Status } \\
\text { Married }^{\dagger} \\
\text { Not married }\end{array}$ & -0.416 & -6.16 to -1.83 & $0.00^{*}$ & -0.381 & -2.85 to -0.76 & $0.01^{*}$ \\
\hline $\begin{array}{c}\text { Educational level } \\
<9 \text { years } \\
>9 \text { years }\end{array}$ & 0.065 & -0.95 to 1.74 & 0.56 & -0.052 & -0.81 to 0.50 & 0.64 \\
\hline $\begin{array}{c}\text { Employment status } \\
\text { Employed }^{\dagger} \\
\text { Unemployed }\end{array}$ & -0.046 & -8.43 to 5.48 & 0.68 & -0.191 & -6.34 to 0.39 & 0.08 \\
\hline $\begin{array}{c}\text { Social class } \\
\text { High }^{\dagger} \\
\text { Low }\end{array}$ & 0.018 & -1.32 to 1.53 & 0.88 & -0.069 & -0.89 to 0.49 & 0.57 \\
\hline $\begin{array}{l}\text { Number of children } \\
\qquad=4^{\dagger} \\
>4\end{array}$ & 0.125 & -0.97 to 3.73 & 0.25 & 0.232 & 0.14 to 2.42 & $0.03^{*}$ \\
\hline $\begin{array}{l}\text { Current living status } \\
\text { Within family setting }^{\dagger} \\
\text { Outside family setting }\end{array}$ & $\begin{array}{c}-0.268 \\
\text { Adjusted } \mathrm{R}^{2}=0.07\end{array}$ & $\begin{array}{c}-3.24 \text { to }-0.36 \\
F=1.98\end{array}$ & $\begin{array}{c}0.02^{*} \\
p=0.06\end{array}$ & $\begin{array}{c}-0.241 \\
\text { Adjusted } \mathrm{R}^{2}=0.12\end{array}$ & $\begin{array}{c}-1.48 \text { to }-0.09 \\
F=2.72\end{array}$ & $\begin{array}{c}0.03^{*} \\
p=0.01\end{array}$ \\
\hline
\end{tabular}

${ }^{\dagger}$ Reference category; *Significant at $(\mathrm{p}<0.05)$; For HIV negative respondents. Difference in TS is best predicted by the marital status and by the current living status. Those not married had a 0.416 unit reduction in perceived TS and 0.381 unit reductions in perceived support from FR compared to those married. And those living outside their family setting had a 0.268 unit reduction in perceived TS and 0.241 unit reduction in perceived support from FR compared to those living in their family settings.

\subsection{Perceived Total Social Support (TS)}

With all respondents analyzed together, the satisfaction with perceived total support of PLWHA compared with HIV negative respondents was best predicted by the HIV status. There was a 0.181 unit reduction in TS scores moving from HIV positives to HIV negative group. When controlling for the effect of HIV status, those not employed among the PLWHA had a poorer perception, thus best predicted their TS scores. This is contrary to previous finding of high perceived social support in PLWHA [12] [20].

Comparing this finding with the HIV negative group, in which marital status and living outside ones family were the best predictors of TS respectively. It is important to note that those not married had lower perceived TS scores in the HIV negative group. This was also reflected in that those living outside their family setting also perceived poorer TS.

Majority of the cohort of PLWHA studied were living within their family setting and may not be experiencing discrimination and stigma from the people they were residing with or the health care personnel they dealt with at the clinic. Which is in agreement that in most developing countries, support is better derived from family setting, or could it be they have learnt to adjust to the negativity in their environment [14] [15]. This may be a very important reason why, only employment status and not marital status or living condition emerged as a significant predictor of TS in the PLWHA.

\subsection{Perceived Social Support from Friends (FR)}

With all respondents analyzed together, the satisfaction with support from FR of PLWHA compared with HIV negative respondents was also best predicted by the HIV status. There was a 0.317 unit reduction in FR scores 
moving from HIV positives to HIV negative group. Not being able to identify a significant predictor of the support of FR scores, for the PLWHA studied compared with HIV negative respondent, may be because, the roles expected to be played by friends have been met within the social network at the clinic, having found friendship in the social network.

It may also mean being satisfied with the support from friends. This may suggest that the PLWHA studied were not totally alienated from their community, and still have a high self-esteem in relating with people as friends and free to associate with them as long as they do not know about their HIV status fearing stigmatization. They also may have come to terms with their health issues, as a form of adjustment and no longer feel different from their friends.

Considering only the HIV negative respondents, those not married had a 0.381 unit reductions in their perceived support from FR. Also reflected in that, those living outside their family setting had 0.241 units reduction in FR scores. It is common in the African setting for women especially, to look up to their children for support. This may also explain why in the HIV negative group, having more children predicted satisfaction with support from FR. In such settings, women abandoned by their husbands, rely on their children for one form of support or the other. Thus, contributing to the understanding of the role of happy marriages and living within an individual's family setting influencing perceived social support.

\subsection{Limitations}

This study was at a single site and so its findings may not be generalized even though various ethnic groups in Nigeria were involved. These cohort of PLWHA studied were already involved in one form of support intervention. Also, only $5 \%$ and $18 \%$ of variance in the perceived TS and FR scores of the respondents could be explained by the independent variables together.

\section{Conclusion}

In this study, both groups of respondents had the poorest perception of support from FA. Unemployment was the most important factor identified in the group of PLWHA that predicted their perceived support. Not being married and living outside their family setting were the strongest predictors of the poor perceived TS and FR in HIV negative respondents.

\section{Recommendations}

More efforts to improve all forms of support for PLWHA should be encouraged. Since both HIV positive and negative group of patients perceived poor support from their family, individuals should be educated on the important roles, family members and friends plays in a disease state. Interventions to improve gainful employment should be incorporated into programs targeting PLWHA.

\section{Acknowledgements}

The authors acknowledge the contributions of Prof. I. F. Adewole, Prof. D. Olaleye, Prof J. Uhaeri, Dr P. O. Olapegba (for making the project possible), Mr Atibioke (data collection) Dr Ayodeji Adebayo (statistical analysis), Dr A. E Irabor and Dr O. Olofin (project supervisors), the entire APIN-UCH staff and staff of Family Medicine Department, University College Hospital, Ibadan, Nigeria.

\section{Authors' Contributions}

OFF designed the study and wrote the article, OA data collection and statistical analysis, EO wrote part of the article.

\section{References}

[1] Yadav, S. (2010) Perceived Social Support, Hope, and Quality of Life of Persons Living with HIV/AIDS: A Case Study from Nepal. Quality of Life Research, 19, 157-166. http://www.iss.it/binary/gend/cont/pubmed.pdf

[2] Galvan, F.K., Davis, E.M., Banks, D. and Bings, E.G. (2008) HIV Stigma and Social Support among African Ameri- 
cans. AIDS Patient Care and STDs, 22, 423-436. http://dx.doi.org/10.1089/apc.2007.0169

[3] Ahmed, S.M. and Lemkau, J.P. (2007) Psychosocial Influences on Health. In: Rakel, R.E., Ed., Textbook of Family Medicine (7th Ed.), Saunders, Elsevier, Philadelphia, 35-40.

[4] Dahlem, N.W., Zimet, G.D. and Walker, R.R. (1991) The Multidimensional Scale of Perceived Social Support: A Confirmatory Study. Journal of Clinical Psychology, 47, 756-761. http://dx.doi.org/10.1002/1097-4679(199111)47:6<756::AID-JCLP2270470605>3.0.CO;2-L

[5] Adedimeji, A.A. and Odutolu, O. Care Support and Quality of Life Outcomes among Persons Living with HIV in the HAART Era; Findings from Southwest Nigeria. http://www.hsph.harvard.edu

[6] Sarason, I.G. and Sarason, B.R. (1986) Experimentally provided Social Support. Journal of Personality and Social Psychology, 50, 1222-1225. http://dx.doi.org/10.1037/0022-3514.50.6.1222

[7] Salter, M.L., Go, V.F., Minh, N.L., Gregowski, A., Ha, T.V., Rudolph, A., et al. (2010) Influence of Perceived Secondary Stigma and Family on the Response to HIV Infection among Injection Drug Users in Vietnam. AIDS Education and Prevention, 22, 558-570. http://dx.doi.org/10.1521/aeap.2010.22.6.558

[8] Reilly, T. and Woo, G. (2004) Social Support and Maintenance of Safer Sex Practices among People Living with HIV/AIDS. Health \& Social Work, 29, 97-105. http://dx.doi.org/10.1093/hsw/29.2.97

[9] Vyavaharkar, M., Moneyham, L., Tavakoli, A., Phillips, K.D., Murdaugh, C. and Jackson, K. (2007) Social Support, Coping, and Medication Adherence among HIV-Positive Women with Depression Living in Rural Areas of the Southeastern United States. AIDS Patient Care and STDs, 21, 667-680. http://dx.doi.org/10.1089/apc.2006.0131

[10] Heckman, T.G., Kochman, A., Shikkema, K.J., Kalichman, S.C., Masten, J. and Goodkin, K. (2000) Late Middle-Aged and older Men Living with HIV/AIDS: Race Differences in Coping, Social Support, and Psychological Distress. Journal of the National Medical Association, 92, 436-444.

[11] Hong, Y., Li, X., Fang, X., Zhao, J., Lin, X., Zhang, J., et al. (2010) Perceived Social Support and Psychosocial Distress among Children affected by AIDS in China. Community Mental Health Journal, 46, 33-43. http://dx.doi.org/10.1007/s10597-009-9201-z

[12] Okawa, S., Yasuoka, J., Ishikwana, N., Pondel, K.C., Ragi, A. and Jimba, M. (2011) Perceived Social Support and the Psychological Well-Being of AIDS Orphans in Yrban. Kenya, AIDS Care, 23, 1177-1185. http://dx.doi.org/10.1080/09540121.2011.554530

[13] Zhao, G., Li, X., Fang, X., Zhao, J., Hong, Y., Lin X., et al. (2011) Functions and Sources of Perceived Social Support among Children affected by HIV/AIDS in China. AIDS Care, 23, 671-679. http://dx.doi.org/10.1080/09540121.2010.525619

[14] Bray, J.H., Campbell, T.L. (2007) The Family’s Influence on Health. In: Rakel, R.E., Ed., Textbook of Family Medicine (7th ed.), Saunders, Elsevier, Philadelphia, 25-32.

[15] Aggleton, P. and Warwick, I. (1999) Household and Community Responses to HIV and AIDS in Developing Countries: Findings from Multi-Site Studies. UNAID, Geneva, 8-15.

[16] Ilebani, O.A. and Fabusoro, E. (2011) Effects of Community-Based Care for People Living with HIV/AIDS on Their Well-Being in Benue State, Nigeria. Research Journal of Medical Sciences, 5, 294-304.

[17] Oluwagbemiga, A.E. (2007) HIV/AIDS and Family Support System: A Situation Analysis of People Living with HIV/AIDS in Lagos State. Journal of Social Aspects of HIV/AID, 4, 668-677. www.sahara.org.za

[18] Friedland, J., Renwick, R. and McColl, M. (1996) Coping and Social Support as Determinants of Quality of Life in HIV/AIDS. AIDS CARE, 8, 15-31.

[19] Adedimeji, A.A., Heard, N.J., Odutolu, O. and Omololu, F.O. (2008) Social Factors, Social Support and Condom use Behavior among Young Urban Slum Inhabitants in Southwest Nigeria. East African Journal of Public Health, 5, 215-222.

[20] Sun, H., Zhang, J. and Fu, X. (2007) Psychological Status, Coping and Social Support of People Living with HIV/ AIDS in Central China. Public Health Nursing, 24, 132-140. http://dx.doi.org/10.1111/j.1525-1446.2007.00617.x

[21] Census 2006 Report (2007) Federal Republic of Nigeria-Official Gazette. Federal Government Printer, Lagos.

[22] Federal Ministry of Health (2010) HIV Sero-Prevalence Sentinel Survey among the Antenatal Clinic Attendees in Nigeria. Abuja, Federal Ministry of Heath.

[23] Sharir, D., Tanasescu, M., Turbow, D. and Maman, Y. (2007) Social Support and Quality of Life among Psychiatric Patients in Residential Homes. International Journal of Psychosocial Rehabilitation, 11, 85-89.

[24] Folasire, O.F., Irabor, A.E. and Folasire, A.M. (2012) Quality of life of People living with HIV and AIDS attending the Antiretroviral Clinic, University College Hospital, Nigeria. African Journal of Primary Health Care \& Family Medicine, 4, 8-16.

[25] Barroffka, A. and Olatawura, M.O. (1977) Community Psychiatry in Nigeria-The Current Status. International 
Journal of Social Psychiatry, 23, 275-281. http://dx.doi.org/10.1177/002076407702300406

[26] Samuel, A., Olowookere, A.A., Fatiregun, A.A., Akinyemi, O.J., Bamgboye, E.A. and Osagbemi, K.G. (2008) Prevalence and Determinants of Nonadherence to Highly Active Antiretroviral Therapy Among People Living with HIV/AIDS in Ibadan, Nigeria. The Journal of Infection in Developing Countries, 2, 369-372.

[27] Olowookere, S.A., Fatiregun, A.A., Ladipo, M.M.A. and Akenova, Y.A. (2011) Reducing Waiting Time at a Nigerian HIV Treatment Clinic: Opinions from and the Satisfaction of People Living with HIV/AIDS. Journal of the International Association of Physicians in AIDS Care, 11, 188-191.

[28] UNAIDS (2007) Facts Sheet, AIDS Epidemic Update, Regional Summary. UNAID. www.unaids.org

[29] UNAIDS (2008) Report on the Global AIDS Epidemic, The Global HIV Challenge. UNAID. www.unaids.org

[30] Olapegba, P.O. (2005) Predicting Mental Health of PLWHA: The Role of Psychosocial Factors. Journal of Human Ecology, 18, 69-72. 